should find a ready welcome wherever vitamin assay is practised. It is finely printed and produced and includes clear diagrams, together with photo-reproductions in black-and-white, and good colour, notably of column and thin-layer chromatography. F. W. Norris

\section{DEVELOPMENT AT THE CELLULAR AND MOLECULAR LEVEL}

\section{Molecular and Cellular Aspects of Development}

Edited by Dr. Eugene Bell. Pp. xi +525. (New York and London: Harper and Row, 1965.) n.p.

T HERE must be many who have been disappointed at the past failure of embryologists and geneticists to establish a common front in the battle for an understand. ing of the role of the gene in ontology. It looks now as if neither, but rather the molecular biologists, are going to be in the front line when the day of the breakthrough dawns. We may have been foolishly impatient in our expectations, overlooking the methodological hurdles in the way of such a straightforward synthesis of geneties and embryology.

The minute analysis, both of the synthetic processes in the development and growth of a complex organism and of the chemical nature, spatial exposition and behaviour of the 'gene' had to await new and dramatic developments in biophysical and biochemical instrumentation, including the advent of the electron microscope. Only then could the stage be set for bridge-building. When this finally happened the molecular biologists naturally had to take the lead.

The collection of fourteen chapters on the theme of Molecular and Cellular Aspects of Development, collected and edited by Dr. Eugene Bell of the Massachusetts Institute of Technology, represents an attempt at a synopsis by no fewer than eighty contributors of progress in the following fields: the study of cell association, induction, cyto-differentiation and cell division, the role of the nucleus, chromosome differentiation, genetic control of differentiation, isozymes, enzyme regulation, RNA synthesis, the synthesis of cell-specific products, macromolecules as the basis of structure, hormones, growth substances and cell-virus interaction. The central topic of the book is cell differentiation, although a number of articles deal also with tissue and organ development. Each of the chapters is introduced by a résumé by the editor covering the problems which form its main theme. The papers themselves are reprints of published articles by outstanding representatives in the field in question.

It is obviously impossible in a short review of such a complex work to deal with any of the individual contributions. Nobody can deny the great difficulties in the dissemination of scientific information, and any attempt to ease access to it ought to be welcomed. The alternatives are a comprehensive review by a single author from a central vantage point, or a herding together of systematically related papers into a work like the present synopsis.

The editor states that he has used this collection of papers for a first course in developmental biology at the Massachusetts Institute of Technology. This is remarkable in view of the rather advanced nature of most of the articles. In browsing through the various chapters, one becomes deeply conscious of the ebullient sense of adventure in present-day biology and of how good it is to be able to witness all this. The ehallenge of attempting the near impossible that has to be accepted in experimental ventures into the realm of molecular happenings, the unfolding of undreamt-of complexities in the form of interlocking self-regulatory systems, the satisfaction to be gained in the design of ingenious experimental and intellectual stratagems, the continuous call for self- criticism in the evaluation of inherently ambiguous observational and statistical results against the backcloth of the great fundamental generalizations governing our theorizing about gene action in the synthesis of proteins and other 'bio' materials, the ordered chaos of tissue and organ determination in embryonic development-- of all this the reader of this book is constantly and excitingly made aware.

Extensive lists of references and 234 well-produced illustrations add to the value of the book, but, apart from a list of contributors, there is no index. The editorial prefaces to the individual chapters read in sequence give coherence to what could otherwise appear to be a rather haphazard collection of reprints. O. LowENSTEIN

\section{COMPUTERS IN MEDICAL RESEARCH}

\section{Computers in Biomedical Research}

Vol. 1. Edited by Ralph W. Stacy and Bruce D. Waxman. Pp. xxii +562. (New York: Academic Press, Inc.; London: Academic Press, Inc. (London), Ltd., 1965.) $160 s$.

I $\mathrm{N}$ the space of a few years biomedical computing and automatic data processing have become a significant part of the biomedical scientific effort ..." This assertion, carried on the dust-cover, is just. An increasing number of important problems in molecular biology, physiology, cardiology and other branches of medicine and its allied sciences are soluble only by extensive mathematical or numerical analysis. Many questions in clinical, social and administrative medicine can be answered only by largescale data processing. Within the past half-decade computers have become not only more powerful and more numerous, but, through the introduction of automatic programming languages, more easy to use. A few pioneers have shown the potentialities of computer science in a wide range of medical applications and have thereby kindled a flame which must grow rapidly in the years to come.

Much of this work has been difficult to follow for those not centrally engaged on it. The publications are scattered and often assume considerable prior knowledge of computer science or the particular field of application. A number of symposia have appeared recently, particularly from the United States, but the presentations have often been too sketchy. Computers in Biomedical Research, Volume 1, and its forthcoming companion, Volume 2, appear to provide the best set of expository papers so far. The range covered is wide and most of the topics are discussed in some depth. Even here, however, a reader like myself, on the fringe of the subject, is likely to have difficulty in entering fully into such diverse topics as enzyme systems, protein structure, statistical analysis, personality assessment and neural processes. The specialist in one of these topics, on the other hand, is likely to ask for more detail, particularly about computing procedures, than can be given in these chapters. Perhaps we now need a series of monographs, each treating one field of medical computation in full detail.

An excellent introduction by the editors is followed by 22 chapters arranged in sections devoted to the life sciences generally, the simulation of biological processes, the analysis of specific systems, and applications to neurophysiology, clinical medicine, psychology and psychiatry. It may be useful here to classify the chapters according to the use to which the computer is put. Three chapters describe extensive data-processing systems: in laboratory medicine (B. Gr. Lamson), in pre-symptomatic screening for many diseases simultaneously (M. F. Collen, L. Rubin and L. Davis) and for automatic personality assessment (H. P. Rome et al.). Several chapters are concerned with complex calculations for diverse purposes: genetics (K-I. Kojima), protein structure analysis (C. L. Coulter), 